\title{
ANÁLISE HISTOLÓGICA, HISTOQUÍMICA E ULTRAESTRUTURAL DA MUSCULATURA DORSAL E VENTRAL DO GUARU (Poecilia vivipara BLOCHI \& SCHNEIDER, 1801)
}

\author{
Ana Paula Rezende dos Santos, ${ }^{1}$ Joana Cristina Neves de Menezes Faria ${ }^{2}$ E \\ Simone Maria Teixeira de Sabóia-Morais ${ }^{3}$ \\ 1. Mestranda em Biologia Celular e Molecular, pela Universidade Federal de Goiás. \\ E-mail: ana p_bio@yahoo.com.br \\ 2. Professora substituta de Biologia Celular e Histologia do Instituto de Ciências Biológicas da UFG \\ 3. Professor associado II da Universidade Federal de Goiás.
}

\section{RESUMO}

Poecilia vivipara (guaru), peixe neotropical de pequeno porte, eurialino, tem sido usado como biomonitor. Analisou-se a musculatura dorsal e ventral do guaru, a fim de se padronizar metodologias para avaliação da estrutura normal deste tecido, com a perspectiva de que sejam usados em estudos de toxicidade. Para tanto, realizaram-se fixações químicas e físicas, que visaram procedimentos histológicos e histoquímicos de coloração e reação. Os métodos H.E. e TM evidenciaram a organização das FMEE, com feixes musculares epiaxial e hipaxial e conjuntivo associado. O AM marcou as FMEE e facilitou a observação dos sarcômeros com a presença de uma fina faixa corada metacromaticamente. Parte das
FMEE foi PAS positiva e amilase reativa, indicando a distribuição de glicogênio entre as fibras. Na presença do SBB, as fibras foram reativas, principalmente na região dorsal, indicando a presença de lipídeos. Na SDH pH 10,5 detectou-se presença de células com citoplasma rico em enzimas mitocondriais. As FMEE coradas com AT apresentaram-se organizadas em faixas transversais alternadas, que correspondem ao padrão visualizado ao MET. O uso destas metodologias permitiu indicar a musculatura do guaru como um instrumento para estudos de variações ambientais, visto que sua estrutura normal é padrão nos teleósteos.

PALAVRAS-CHAVES: Fibra muscular, morfologia, peixe neotropical.

\section{ABSTRACT}

\section{HISTOLOGICAL, HISTOCHEMICAL AND ULTRASTRUCTURAL ANALYSIS OF THE DORSAL AND VENTRAL MUSCU- LATURE OF THE GUARU (Poecilia vivipara BLOCHI \& SCHNEIDER, 1801)}

Poecilia vivipara (guaru), a neotropical, small, euryhaline fish, has been being used as a biomonitor. Dorsal and ventral muscles of Poecilia vivipara were analyzed to standardize methodologies for evaluating the normal tissue structure, in order to use them in toxicity studies. Thus, chemical and physical fixations were carried out, aiming at the histological and histochemical procedures of staining and reaction. The methods HE and MT revealed the organization of SSMF with epiaxial and hypaxial muscle bundles and associated conjunctive. MA marked the SSMF and facilitated the observation of sarcomeres in the presence of a thin metacro- matically stained band. Part of the SSMF was positive PAS and reactive amylase, indicating the distribution of glycogen within the fibers. In the presence of SBB the fibers were reactive mainly in the dorsal region, indicating the presence of lipids. Cells with mitochondrial enzyme-rich cytoplasm were found in SDH pH 10.5. The SSMF stained with AT were arranged in alternating transverse bands, which correspond to the pattern seen under the MET. The use of these methodologies allowed the indication of Poecilia vivipara muscles as a tool for environmental variations studies, because its normal structure is standard in teleosts.

KEYWORDS: Morphology, muscle fiber, neotropical fish. 


\section{INTRODUÇÃO}

O movimento em organismos multicelulares é desempenhado por células especializadas, as fibras musculares, e contraem-se de acordo com estímulos apropriados (HUXLEY, 1954). Os estímulos desencadeiam ativações moleculares e permitem que conjuntos de proteínas contráteis respondam de forma eficaz, na dependência de energia e funcionalidade de outras moléculas para desempenharem sua atividade (ALEXANDER, 2004).

A organização das fibras musculares em peixes elasmobrânquios e teleósteos corresponde a um músculo axial, constituído principalmente de fibras brancas-rápidas, que são cobertas por uma camada fina de fibras musculares vermelhas-lentas, com uma camada de fibras-rosa entre elas (SANTOS, 2007). As fibras vermelhas possuem alta capacidade aeróbica e contração lenta, tendo a cor do músculo relação como grau de vascularização das fibras, em consequência da grande quantidade de mioglobinas e citrocromos (KIESSLING et al., 2006). As fibras brancas possuem alta capacidade anaeróbica e glicolítica, além de rápida contração, correspondendo nunca menos que $70 \%$ dos músculos esqueléticos (SÄNGER \& STOIBER, 2001; CEDIEL et al., 2008). Mitocôndrias, que interrompem a organização das miofibrilas, são poucas, bem como gotas lipídicas e mioglobinas estão presentes em pequena quantidade (KIESSLING et al., 2006). As fibras rosas, ou intermediárias em jovens e adultos de teleósteos, estão entre as fibras musculares branca e vermelha. Caracterizam-se pela rápida contração, resistência à fadiga e velocidade de encurtamento (KIESSLING et al., 2006).

A presença de um ou mais tipos de fibras e a distribuição e frequência dos subtipos são determinantes das características metabólicas e contráteis do músculo esquelético, revelando suas propriedades bioquímicas e fisiológicas. É válido ressaltar que o fenótipo definitivo de fibras musculares esqueléticas adultas é resultado de eventos que começam no embrião e são modulados no decorrer da vida do organismo (SARTORI et al., 2001).

O conhecimento quantitativo da composição química dos músculos de peixes de interesse comercial é importante para a formulação de dietas apropriadas, para a definição de procedimentos técnicos e para as indústrias de processamento de pescado (SALES \& SALES, 1990).

O estudo dos componentes biológicos em peixes tem sido utilizado como bioindicador de qualidade ambiental. Substâncias tóxicas lançadas no ambiente por ações antrópicas fazem com que estes interajam com o organismo vivo, provocando alterações que podem gerar graves desequilíbrios ecológicos (ARIAS et al., 2007). Segundo SELLANES et al. (2002), a musculatura de peixes serve para monitoramento dos teores de mercúrio total nos organismos aquáticos utilizados para consumo humano, tanto pelas autoridades sanitárias quanto pela sociedade, por ações antrópicas.

Diversos estudos têm sido realizados com o intuito de se verificar a acumulação tanto de mercúrio quanto de outros metais pesados (SELLANES et al., 2002; PLOETZ et al., 2007; SEIXAS et al., 2007). Para averiguar o grau de contaminação de ambientes aquáticos por metais pesados $\mathrm{Zn}, \mathrm{Cu}, \mathrm{Mn}$ e $\mathrm{Cd}$, foram realizados estudos de monitoramento da concentração desses metais no fígado, pele e músculo do Lethrinus lentjan (LACEPÉDE, 1802), constatando-se que as maiores concentrações de cádmio foram encontradas no fígado e no músculo, sugerindo que tais tecidos são bons bioindicadores (AL-YOUSUF et al., 2000).

O pescado, quer de água doce, quer marinho, não tem sido fiscalizado de maneira sistemática como é necessário, por órgãos oficiais, conforme KITAHARA et al. (2000), o que justifica o uso de espécimes forrageiros como biomonitores em condições ambientais naturais ou no cativeiro.

Neste estudo, foi utilizado como elo biológico o guaru, recebendo outras denominações vulgares no Brasil segundo IHERING (1931). Sua classificação taxonômica obedeceu aos critérios de ROSEN \& CORNFORD (1963), como segue: Poecilia vivipara, pertencentes à ordem Cyprinodontiformes e à família Poeciliidae.

Os guarus são espécimes larvófagos, onívoros e cosmopolitas do continente americano, usados como espécimes forrageiros em criadouros de peixes. $\mathrm{O}$ fato de serem eurialinos, ou seja, responderem e se adaptarem a variações de salinidade nos corpos d'água, permite que estes sejam responsivos às condições adversas do ambiente aquático (SABÓIA-MORAIS, 1996).

A proposta deste trabalho foi estudar a distribuição histológica das fibras musculares estriadas 
esqueléticas na musculatura dorsal e ventral do $P$. vivipara, analisar respostas de fibras constituintes destes músculos através do uso de histoquímica e determinar o procedimento de fixação e meio de inclusão que melhor preserve a morfologia e os sítios de reação para fins de contribuir com a biologia da conservação.

\section{MATERIAL E MÉTODOS}

Coletaram-se seis fêmeas adultas guarus em tanques específicos (16 35'37'S e 49 16'50” W), sendo transferidas para o Laboratório de Comportamento Celu$\operatorname{lar}$ (LCC). Foram aclimadas durante 48 horas em aquários de quarenta litros, dotados de aeração promovida por bombas de ar, com temperatura da água mantida a $\pm 27^{\circ} \mathrm{C}$. O fotoperíodo (claro/escuro) era de ciclos com 12:12 horas. O quantitativo de amônia dissolvida na água era de 0 $\mu 1 / \mathrm{L}$ a $0,01 \mu / \mathrm{L}$. A alimentação diária foi feita com ração comercial (Alcon COLOURS $®$ ). Removeram-se restos de alimento e fezes diariamente, com sifão, seguindo-se de reposição do volume da água.

Os guarus foram expostos à hipotermia, decapitados, eviscerados e tiveram sua musculatura total fixada em diferentes soluções como paraformaldeído a $10 \%$ e em tampão fosfato $0,1 \mathrm{M}, \mathrm{pH} 7,4$ over night, também em Bouin, Carnoy, Zenker, e McDowell. Incluíram-se alguns fragmentos de músculo em parafina e outros em historresina (Historresina Leica - USA), sendo seccionados a 4 e $2 \mu \mathrm{m}$, respectivamente.

Submeteu-se o material cortado aos métodos histológicos: hematoxilina e eosina, azul de toluidina + floxina, azul de metileno e tricrômico de masson, para ser observada a organização geral das fibras musculares.

Para a análise histoquímica foram utilizados: ácido periódico Schiff (PAS), com a finalidade de detectar glicoconjugados neutros, e diastase + PAS, para diagnosticar a presença de glicogênio.

Realizou-se Sudan Black B para se verificar a distribuição e a quantidade de lipídeos. A análise da tipagem muscular foi feita por meio da técnica succinodesidrogenase em $\mathrm{pH}$ 10,5, após pré-incubação ácida ( $\mathrm{pH} 4,6)$, para a detecção de enzimas mitocondriais e com isso ser diagnosticado o tipo de contração (rápida ou lenta) que a fibra muscular apresenta.

Para análise do material em microscopia eletrônica, o tecido foi imediatamente imerso em uma solução fixadora por $2,5 \%$ de glutaraldeído (GTA) + $4 \%$ tampão fosfato (PFA) em tampão cacodilato de sódio $0,1 \mathrm{mmol} / \mathrm{L}, \mathrm{pH} 7,4$, por três horas a $4^{\circ} \mathrm{C}$.

Em seguida, o material passou por um processo de pós-fixação em $\mathrm{OsO}_{4} 2 \%$ por uma hora. Após a desidratação, o tecido muscular foi embebido em resina Spurr. As secções semifinas com 0,5 $\mu \mathrm{m}$ de espessura foram coradas com azul de toluidina. Posteriormente, os cortes ultrafinos com $70 \mathrm{~nm}$ de espessura foram contrastados com acetato de uranila $0,5 \%$ e citrato de chumbo $1 \%$ e analisados no microscópio eletrônico de transmissão (Jeol 1200 EXII).

\section{RESULTADOS}

Em análise dos meios de fixação propostos, detectou-se que o fixador mais adequado para o tecido em estudo foi o paraformaldeído a $10 \%$ em tampão fosfato $0,1 \mathrm{M}, \mathrm{pH} 7,4$. O Bouin, Zenker e o Carnoy não foram eficientes para a preservação do tecido muscular em todos os sítios estudados. A fixação realizada com uso de crioprotetor associado a nitrogênio líquido caracterizou-se como eficaz para a preservação das proteínas e outros componentes químicos.

A historresina mostrou-se como o meio de inclusão química mais adequado, visto que se manteve a morfologia tecidual, com melhores resultados do que a parafina. A coloração pelo tricrômico de Masson possíbilitou observar a estrutura geral dos feixes musculares, cuja coloração vermelha intensa marcou todas as fibras musculares epiaxiais e hipoaxiais (Figura 1). Nas fibras da região epiaxial, a organização dos miótomos apresentou-se com maior adensamento em relação à porção hipaxial. Foi possível perceber na região dorsal a presença de duas estruturas musculares denominadas supracarinalis, as quais, segundo WINTERBOTTOM (1974), são como feixes de cordões pareados, que se localizam ao longo da região dorsal e interconectam os elementos de suporte das nadadeiras pares e mediana. Estas são individualizadas do restante dos miótomos hipoaxiais por tecido conjuntivo denso. Observou-se também que os feixes musculares encontram-se envolvidos por fibras colágenas (Figura 1).

Os miótomos epiaxiais mostraram-se subdivididos por um septo de tecido conjuntivo denominado septo vertical, o qual formou um eixo divisor desde a região dorsal até a coluna vertebral, do qual partiram 
feixes de fibras colágenas que subdividiam os miótomos (Figura 1).

Nos cortes corados em HE, as fibras musculares mostraram-se acidófilas (Figura 2), ao passo que seus núcleos periféricos eram basófilos.

A coloração azul de metileno evidenciou fibras musculares organizadas segundo um padrão de faixas transversais alternadas, coradas em tons crescentes de azul com uma fina faixa corada metacromaticamente (Figura 3).

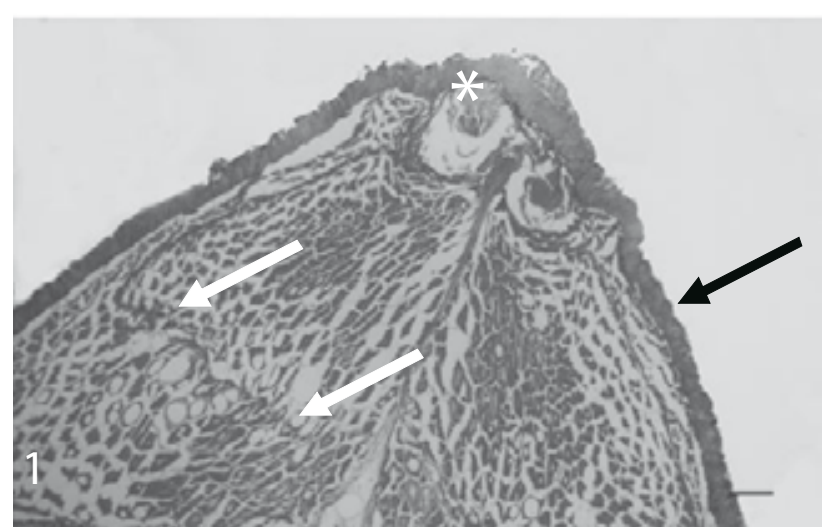

FIGURA 1. Aspecto panorâmico da musculatura axial do Poecilia vivipara, mostrando músculos supracarinalis (asterisco), epiderme (seta preta), mioseptos (seta branca). Tricrômico de Masson. Barra $=100 \mu \mathrm{m}$.

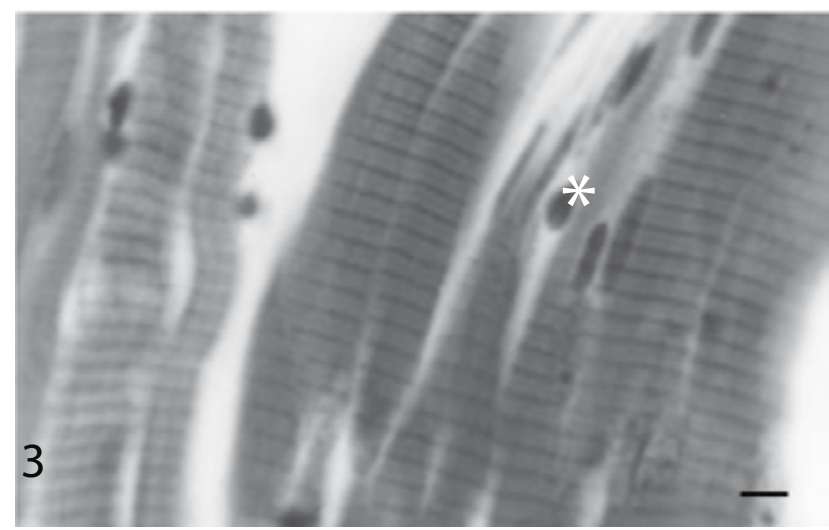

FIGURA 3. Secção longitudinal das fibras musculares. Observamse faixas metacromáticas correspondentes à banda I e regiões ortocromáticas nas posições da banda A. São frequentes os núcleos alongados (asterisco). Azul de metileno. Barra $=50 \mu \mathrm{m}$
Na coloração pelo azul de toluidina junto com a floxina, as bandas A das miofibrilas estavam representadas como espessas listras verticais violetas, em virtude do padrão de metacromasia. As bandas claras estiveram coradas em azul e nesta as bandas I foram atravessadas por linhas escuras denominadas linhas Z. Estas igualmente apresentam padrão metacromático, dividindo uma banda I em duas hemibandas. Os núcleos localizam-se perifericamente nas fibras e apareceram corados em azul intenso (Figura 4).

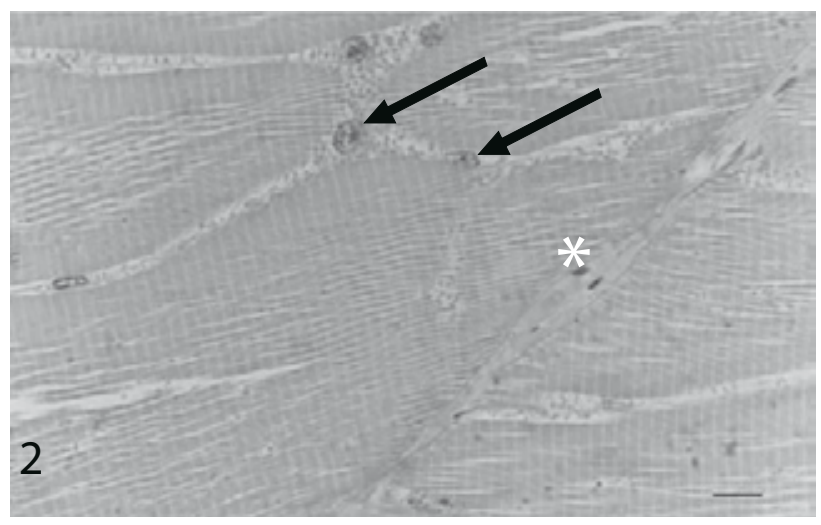

FIGURA 2. Fibras musculares em corte oblíquo. Nota-se a presença de septos de conjuntivo (asterisco), sarcômeros dispostos superficialmente e núcleos das fibras (setas). H.E. Barra $=25 \mu \mathrm{m}$.

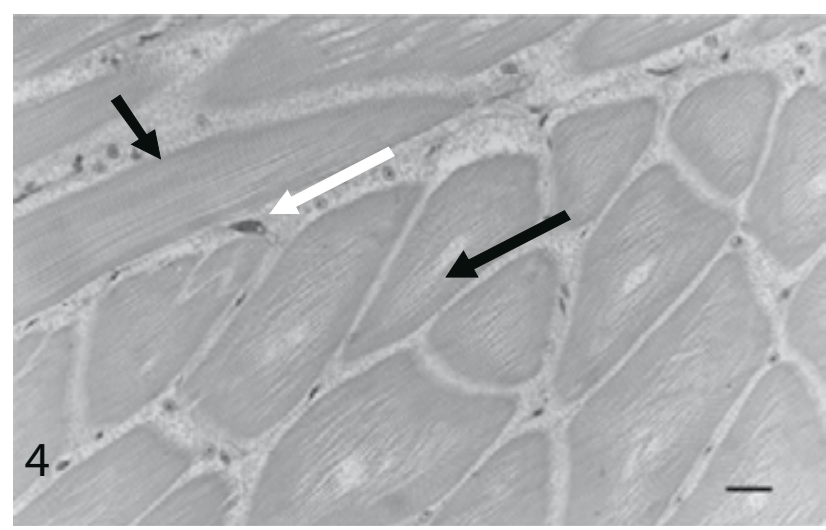

FIGURA 4. Secção longitudinal e transversal das fibras musculares, apresentando padrão metacromático, com as bandas A escuras e bandas I claras, com núcleos de fibroblastos no endomísio (seta branca) secção longitudinal (seta preta curta) e secção transversal (seta preta longa) das fibras musculares e núcleos periféricos das fibras (cabeça de seta). Azul de toluidina e floxina. Barra $=50 \mu \mathrm{m}$. 
Pelo PAS (ácido periódico Schiff), foi possível a identificação das fibras glicolíticas, ou seja, fibras musculares que possuem o glicogênio em grande quantidade e são de contração lenta (fibras vermelhas). As fibras musculares esqueléticas reagiram de forma distinta ao PAS. As regiões epiaxial e superficial apresentaram maior positividade ao reativo, apesar de haver regiões em que foi possível se observar uma mistura de fibras com diferentes padrões de reatividade (Figura 5a). Nos cortes que foram submetidos ao bloqueio pela diástase, constatou-se que o conteúdo tratava-se de glicogênio, uma vez que elas não foram reativas ao PAS, após a atividade enzimática ter se realizado (Figura $5 b$ ).
A musculatura esquelética do guaru apresentou positividade para a reação do Sudan Black B, que faz a marcação de lipídeos. Tanto na região dorsal quanto ventral do peixe, constatou-se a presença de fibras ricas em miofilamentos reativos aos Sudan Black B, sendo que a positividade é maior em fibras vermelhas (Figura 6).

Pela succinodesidrogenase $(\mathrm{SDH}) \mathrm{pH} 10,5$, foi confirmada a presença de células com citoplasma pobre em enzimas mitocondriais na porção ventral, ou seja, onde havia fibras brancas (Figura 7), havia muitas fibras musculares reativas, principalmente na região epiaxial, rica em fibras vermelhas.
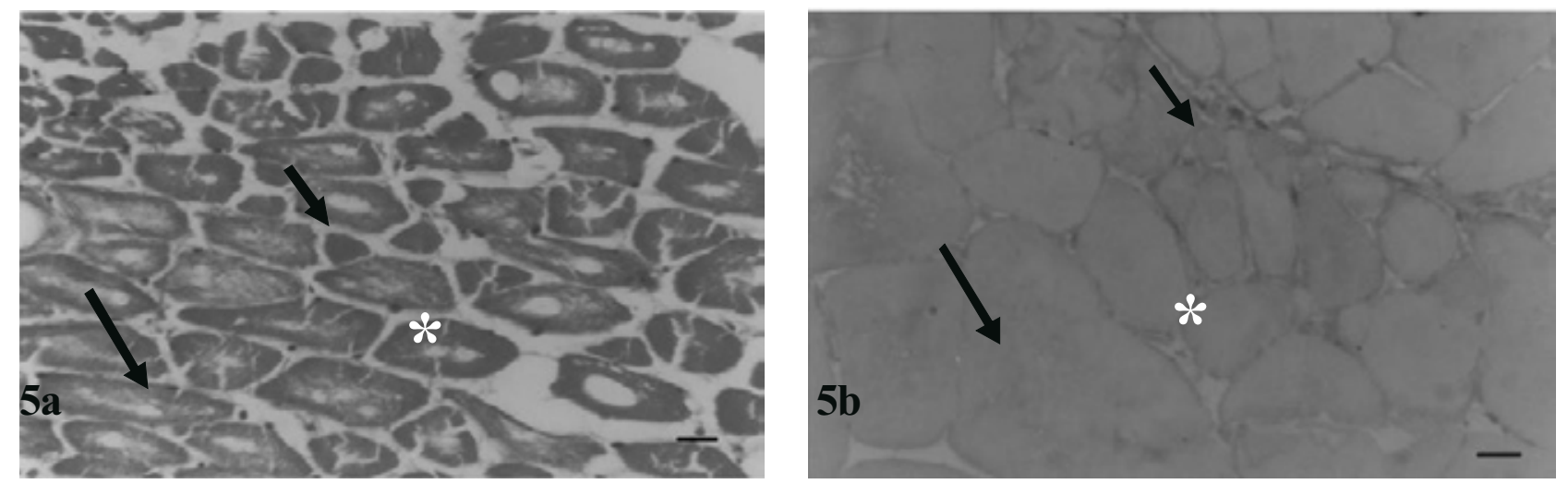

FIGURA 5. Cortes transversais com mosaico de fibras musculares esqueléticas onde há reatividade positiva para glicogênio. a) e b) É possível se distinguir as fibras vermelhas (seta menor), brancas (seta maior) e intermediárias [*], com diferenças relativas ao diâmetro e à intensidade de reação; b) observa-se que as fibras são amilase reativas. PAS. Barra $=50 \mu \mathrm{m}$.

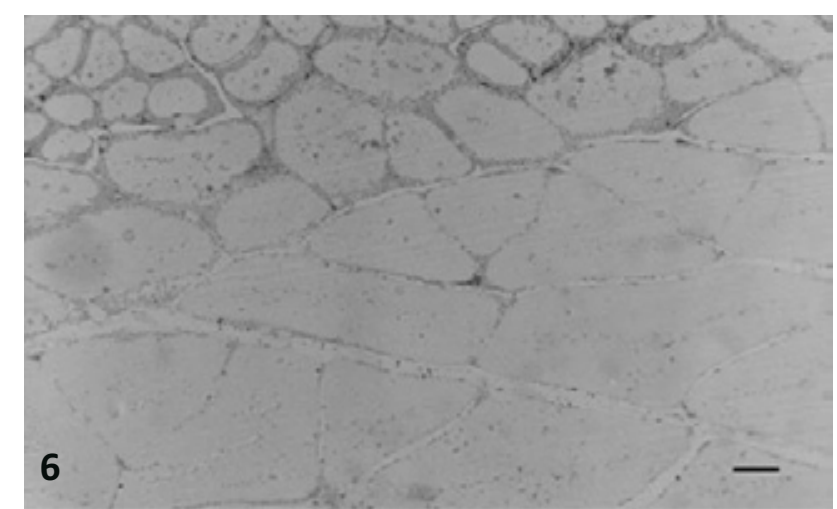

FIGURA 6. Distribuição de tipos de fibras da região mais superficial para a mais profunda. Observa-se reatividade positiva na superfície externa, onde se verificam fibras de diâmetro menor (asterisco) e a diminuição da reatividade ao mesmo tempo em que o diâmetro das fibras vai aumentando. Sudan Black B. Barra $=50 \mu \mathrm{m}$.

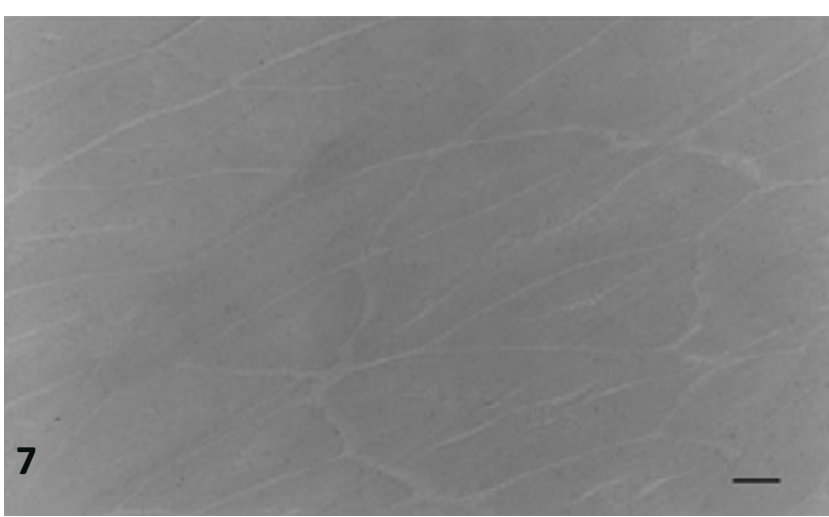

FIGURA 7. Reação confirmativa para fibras brancas. Succinodesidrogenase. Barra $=50 \mu \mathrm{m}$. 
A microscopia eletrônica de transmissão possibilitou observar os sarcômeros repetindo-se ao longo da miofibrila, separados por duas estrias finas e eletrondensas, as chamadas linhas $\mathrm{Z}$, e estando presentes neste espaço a banda A e dois segmentos de banda I (Figura 8). E entre as miofibrilas foi possível notar a presença de retículo sarcoplasmático e mitocôndrias, as quais se localizavam com grande frequência na região adnuclear e nas proximidades do sarcolema (Figura 9).

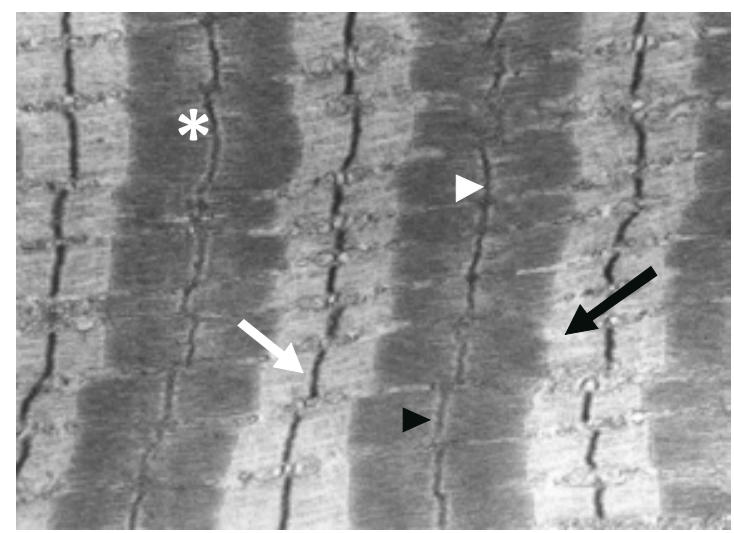

FIGURA 8. Eletromicrografia mostrando fibra muscular relaxada. Visualiza-se o arranjo das proteínas contráteis (miofilamento) em cada sarcômero, em fibras brancas. Entre duas linhas Z [seta branca] encontra-se uma banda clara, denominada banda I [seta preta], composta por filamentos finos de actina, e entre as bandas I encontra-se a banda A [*], mais escura, onde ocorre uma sobreposição de filamentos finos com filamentos espessos de miosina. No centro da banda A está a linha M [cabeça de seta branca], e a circundá-la encontra-se uma faixa estreita, mais clara, designada banda $\mathrm{H}$ [cabeça de seta preta], onde se encontram filamentos de miosina. Aumento: 18,700 X.

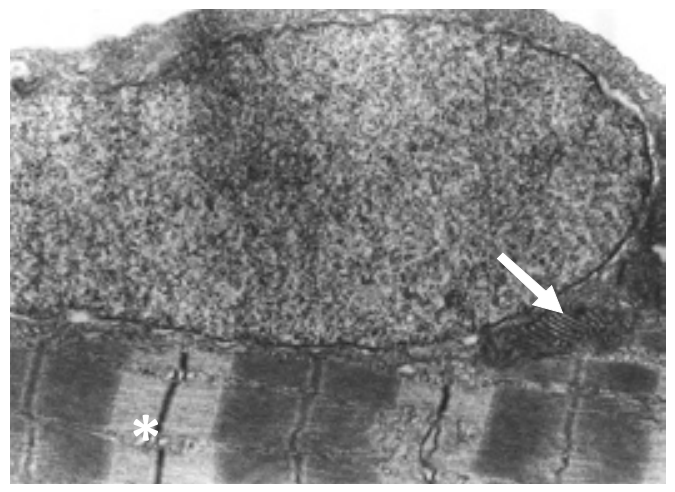

FIGURA 9. Entre as miofibrilas foi possível notar a presença de retículo sarcoplasmático $\left({ }^{*}\right)$ e mitocôndrias (seta branca), as quais se localizavam com grande frequência na região adnuclear e nas proximidades do sarcolema. Aumento: 18,700 X.

\section{DISCUSSÃO}

Ao comentar os resultados deste estudo, podese entender que a padronização do método de fixação é essencial para que trabalhos de análise quantitativa e qualitativa em músculo de peixes sejam realizados com segurança, posto que a metodologia inadequada de fixação leva à obtenção de resultados discrepantes (EGGINTON \& CORDINER, 1995).

O Bouin, em virtude de suas propriedades coagulantes (AMARAL et al., 2004), não preservou o tecido muscular, pois promoveu retração dos miótomos e das fibras, desordenando a morfologia tecidual. O mesmo foi aceito para o Zenker e para o Carnoy. Entendeu-se que isso se deva aos sítios de preservação que estes fixadores promovem.

O bom resultado obtido com paraformaldeído a $10 \%$ em tampão fosfato $0,1 \mathrm{M}, \mathrm{pH}$ 7,4 provavelmente se deva à sua capacidade de manutenção da química das estruturas proteicas. O mesmo observado com a crioproteção, que manteve a morfologia do tecido de forma satisfatória. Tais dados estão de acordo com TAKAHASHI (1988), que indicou que a boa preservação de proteínas e enzimas musculares é feita pela fixação física e por poucas misturas fixadoras químicas, das quais as mais indicadas são as que possuem aldeídos em sua composição.

A historresina foi considerada neste estudo como o mais adequado método de inclusão química, primeiramente em razão da temperatura de processamento do material. Além de outras vantagens como a polimerização à temperatura ambiente, além de a resina permitir a fácil integração dos cromógenos com os sítios ligantes. Isto possibilita a realização de cortes mais finos e consequentemente maiores detalhes nas análises feitas.

A parafina, ao exigir temperatura em torno de $65{ }^{\circ} \mathrm{C}$, promoveu a retração do tecidos muscular, bem como a desnaturação protéica, o que no caso deste estudo foi desvantajoso.

O padrão geral de organização das fibras musculares esqueléticas dos vertebrados, quando analisadas sob luz polarizada, mostrou diferenças quanto à refringência. As bandas coradas em escuro birrefringentes, denominadas anisotrópicas, correspondem à banda $\mathrm{A}$, ao passo que as claras são isotrópicas e correspondem às bandas I (BARRAL \& EPSTEIN, 1999). 
Esse perfil é semelhante ao descrito por BARRAL \& EPSTEIN (1999), por ocasião da utilização da coloração azul de toluidina, em que foi possível visualizar as bandas A coradas em violeta e as bandas I em azul, representando um padrão metacromático na miofibrila, que refletiu a refringência observada por meio da luz polarizada.

As fibras musculares posicionadas na periferia dos feixes musculares, ou seja, na região epiaxial e lateral do guaru, apresentaram maior positividade ao PAS, em relação à porção hipaxial, sendo essa reação indicativa da presença de glicoproteínas neutras e glicogênio. No PAS, ocorreu a oxidação aos grupamentos 1-2 glicol, produzindo aldeídos, e estes foram reagentes com a fucsina descorada, chamada de reativo de Schiff, dando um composto de adição, violeta e insolúvel. Esse mesmo resultado foi obtido por KIESSLING et al. (2006), em análise do padrão de distribuição de glicogênio ao longo de toda a musculatura de peixes teleósteos. Estas fibras, segundo os autores referidos, são vermelhas e de contração lenta.

A positividade ao Sudan Black B, que identifica lipídeos, ocorreu principalmente nas fibras posicionadas nas regiões dorsal e lateral. Da mesma forma como ocorreu a reatividade ao PAS. Pode-se, portanto, inferir que estas fibras são vermelhas e desempenham um trabalho lento, de longa duração, com pouco gasto de energia adquirida através do metabolismo oxidativo, que caracteristicamente estas fibras contêm (DAL PAI et al., 2000; SANTOS, 2007).

Observou-se que fibras musculares não reativas às SDH localizaram-se principalmente nas regiões ventral ou hipaxial do guaru. Essa reação é indicativa de células com citoplasma rico em enzimas mitocondriais, sugerindo que as regiões não reativas são constituídas por fibras musculares brancas (CHAUVIGNÉ et al., 2005; SANTOS, 2007).

As fibras vermelhas dos guarus apresentaram maior reatividade ao $\mathrm{SDH}$ em relação às fibras rosa e branca, que foram fracamente reativas. Esses dados estão em consonância com os obtidos por THÉBAULT et al. (2005), que, em estudo histoquímico e enzimático da musculatura do teleósteo Scyliorhinus canicula (Linnaeus, 1758), observaram que as fibras vermelhas possuíam maior reatividade ao $\mathrm{SDH}$ em relação às fibras rosa e branca, que foram fracamente coradas. Neste mesmo estudo, constatou-se que a NADH possui reação compatível à obtida para $\mathrm{SDH}$, o que permite supor que em musculatura de peixes o emprego de uma das duas metodologias é suficiente para se analisar as reações e a tipagem das fibras musculares.

Nas análises ao M.E.T., foi possível perceber que são encontradas mais fibras ricas em mitocôndrias na região dorsal da musculatura do que na região ventral. De acordo com SANTOS (2007), a grande quantidade de mitocôndrias dessas fibras se deve à alta capacidade aeróbia que as fibras vermelhas possuem.

\section{CONCLUSÃO}

Diante do exposto, sugere-se que as distribuições de fibras musculares do guaru podem ser usadas para detectar reações adversas a agentes intervenientes indesejáveis na água, uma vez que estes poderiam interferir na organização e disposição normais de proteínas, lipídeos e polissacarídeos distribuídos nas fibras musculares estriadas esqueléticas. $\mathrm{O}$ guaru seria um biomonitor, sendo que as alterações na distribuição de fibras musculares poderiam indicar processos de intoxicação do animal relacionados a alterações ambientais.

\section{REFERÊNCIAS}

ALEXANDER, R. M. Models and the scaling of energy costs for locomotion. The Journal of Experimental Biology, v. 208, n. 9, p. 1645-1652, 2004.

AL-YOUSUF, M. H.; EL-SHAHAWI, M. S; AL-GHAIS, S. M. Trace metals in liver, skin and muscle of Lethrinus lentjan fish species in relation to body length and sex. The Science of the Total Environment, v. 256, n. 2-3, p. 87-94. 2000.

AMARAL, D.; CHIARINI-GARCIA, H.; VALE FILHO, V. R.; ALLE, W. R. Efeito dos fixadores formalina e Bouin na preservação de biópsias do endométrio de égua após inclusão em resina plástica. Arquivos Brasileiros de Medicina Veterinária e Zootecnia, v. 56, n. 1, p. 7-12. 2004.

ARIAS, A. R. L.; BUSS, D. F. B.; ALBURQUERQUE, C.; INÁCIO, A. F.; FREIRE, M. M.; EGLER, M.; MUGNAI, R.; BAPTISTA, D. F. Use of bioindicators for assessing and monitoring pesticides contamination in streams and rivers. Ciência \& Saúde Coletiva, v. 12, n. 1, p. 61-72. 2007.

BARRAL, J. M.; EPSTEIN, H. F. Protein machines and self assembly in muscle organization. Bioessays, v. 21, n. 10, p. 813-823. 
CEDIEL, R.A.; BLOB, R.W.; SCHRANK, G.D.; PLOURDE, R.C.; SCHOENFUSS, H.L. Muscle fiber type distribution in climbing Hawaiian gobioid fishes: ontogeny and correlations with locomotor performance. Zoology, v. 111, n. 2, p. 114-122. 2008.

CHAUVIGNÉ, F.; RALliERE, C.; CAUTY, C.; RESCAN, P. Y. In situ hybridization of a large repertoire of muscle-specific transcripts in fish larvae: the new superficial slow-twitch fibres exhibit characteristics of fast-twitch differentiation. The Journal of Experimental Biology v. 209, n. 2, p. 372-379, 2006.

DAL PAI, V.; DAL PAI-SILVA, M.; CARVALHO, E. D.; FUJIHARA, C. Y.; GREGÓRIO, E. A.; CURI, P. R. Morphological, Histochemical and Morphometric Study of the myotomal muscle tissue of the Pacu (Piaractus mesopotamicus Holmberg 1887: Serrasalminae, Characidae, Teleostei). Anatomia, Histologia, Embryologia, v. 29, n. 7, p. 283-289, 2000.

EGGINTON, S.; CORDINER, S. Effect of fixation protocols on muscle preservation an in situ diffusion distances. Journal of Fish Biology, v. 47, n. 1, p. 59-69, 1995.

HUXLEY, H. E.; HANSON, T. Changes in the cross striations of muscle during contraction and stretch and their structural interpretation. Nature, v. 173, n. 4412, p. 973-976, 1954.

IHERING, R. V. Cyprinodontiformes brasileiros (peixes "Guaru”), sistemática e informações biológicas. Archives Institute of Biology, v. 4, p. 243-280, 1931.

KIESSLING, A.; RUOHONEN, K.; BJØRNEVIK, B. Muscle fibre growth and quality in fish. Archives Tierzucht, Dummerstorf, v. 49, p. 137-146, 2006.

KITAHARA, S. M.; OKADA, I. A.; SAKUMA, A. M.; ZENEBON, O.; JESUS, R. S.; TENUTA-FILHO, A. Mercúrio total em pescado de água-doce. Ciência e Tecnologia de Alimentos, v. 20, n. 2 , p. $267-273,2000$.

MADEIRA, L. A.; SARTORI, J. R.; SALDANHA, E. S. P. B.; PIZZOLANTE, C. C.; SILVA, M. D. P.; MENDES, A. A.; TAKAHASHI, S. E.; SORTE, W. V. N. Morfologia das fibras musculares esqueléticas de frangos de corte de diferentes linhagens criados em sistemas de confinamento e semiconfinamento. Revista Brasileira de Zootecnia, v. 35, n. 6, p. 2322-2332, 2006.

PLOETZ, D. M.; FITTS, B. E.; RICE, T. M. Differential accumulation of heavy metals in muscle and liver of a marine fish (King
Mackerel, Scomberomorus cavalla Cuvier) from the Northern Gulf of Mexico, USA. Bulletin of Environmental Contamination and Toxicology, v. 78, n. 2, p. 134-137, 2007.

ROSEN, M. W.; CORNFORD N. E. Fluid friction of fish slimes. Nature, v. 234, p. 49-51, 1971

SABÓIA-MORAIS, S. M. T.; HERNANDEZ-BLAZQUEZ, F. J; MOTA, D. L.; BITTENCOURT, A. M. Mucous cell types in the branchial epithelium of the euryhaline fish Poecilia vivipara. Journal of Fish Biology, v. 49, n. 3, p. 545-548, 1996.

SALES, R. O.; SALES, A. M. Estudo da composição química e rendimento de dez espécies de pescado de água doce de interesse comercial nos açudes do nordeste brasileiro. Ciências Agronômicas, v. 1-2, n. 21, p. 27-30, 1990.

SANTOS, V. B. Aspectos morfológicos da musculatura lateral dos peixes. Boletim do Instituto de Pesca, v. 33, n. 1, p. 127-135, 2007.

SARTORI, J. R.; GONZALES, E.; DAL PAI, V.; OLIVEIRA, H. N.; MACARI, M. Efeito da temperatura ambiente e da restrição alimentar sobre o desempenho e a composição de fibras musculares esqueléticas de frango de corte. Revista Brasileira de Zootecnia, v. 30, n. 6, p. 1779-1790, 2001.

SEIXAS, T. G. M.; MOREIRA, I. M.; KEHRIG, H. A. M.; MALM, O. Distribuição de selênio em organismos marinhos da Baía de Guanabara/ RJ. Química Nova, v. 30, n. 3, p. 554-559, 2007.

SELlANES, A. G.; MARSICO, E. T.; SANTOS, N. N.; CLEMENTE, S. C. S.; OLIVEIRA, G. A.; MONTEIRO, A. B. S. Mercúrio em peixes marinhos. Acta Scientiae, v. 30, n. 2, p. 107-112, 2002.

TAKAHASHI, T.; HISH, A.; ERBE, E.; WILLIAMS, R. J. Mechanism of cryoprotection by extracellular polymeric solutes. Biophysical Journal, v. 54, n. 3, p. 509-518.

THÉBAULT, M. T.; IZEM, L; LEROY, J. P; GOBIN, E; CHARRIER, G; RAFFIN, J. P. AMP-deaminase in elasmobranch fish: a comparative histochemical and enzymatic study. Comparative Biochemistry and Physiology Part B, v. 141, n. 4, p. 472-479. 2005.

WINTERBOTTOM, R. A descriptive synonymy of the striated muscles of the. Teleostei. Proceeding of the Academy of Natural Sciences of Philadelphia, v. 125, n. 12, p. 225-317, 1974. 